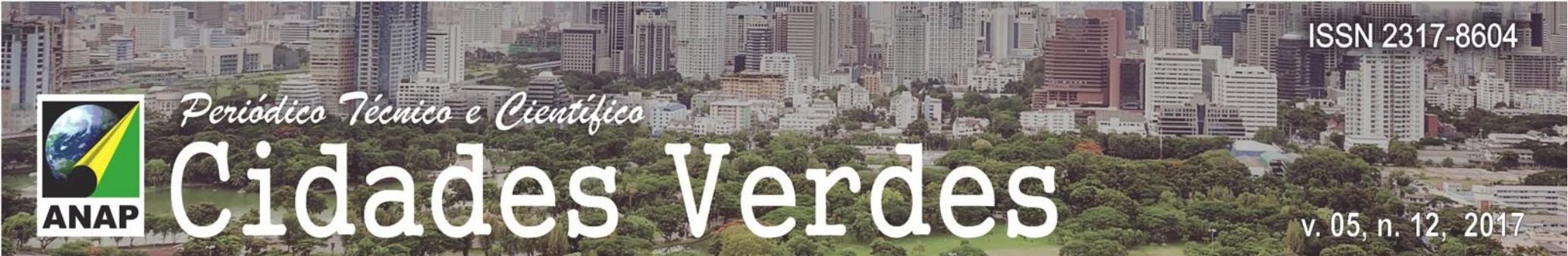

\title{
Argamassa Ecológica Leve Para Regularização de Contrapiso.
}

Lightweight Ecological Mortar for Subfloor Regularization.

Mortero Ecológico Ligero para Regularización de contrapiso.

\section{Thiago Francisco Silva Trentin \\ Professor Mestre Eng. Civil, UNIP, Brasil} thiago.trentin@tecnobens.com.br

\section{Gislaine Bianchi}

Professor Esp. Arq. Urb., UNIP, Brasil. gbianchi.arq@gmaili.com

\section{Diego Valverde}

Graduando, UNILINS, Brasil. diegoaugvalverde@gmail.com

\section{Diego Borges}

Engenheiro Civil, Bilac, Brasil borges_diego08@hotmail.com

Jorge Luís Akasaki

Professor Doutor Eng. Civil, UNESP, Brasil

jorge.akasaki@gmail.com 


\section{RESUMO}

A utilização de argamassa cimenticia é amplamente difundida nas obras. A argamassa é utilizada para o assentamento de blocos, emboço e reboco de paredes e para enchimento de contrapiso e rebaixos de banheiros. Nesses dois últimos casos, quanto mais leve for a argamassa melhor para a estrutura portante, uma vez que, o carregamento devido ao peso próprio será melhor. Para reduzir o peso das argamassas de enchimento existem alguns materiais que podem ser utilizados como agregado leve, tais como: EPS, Vermiculita e argila expandida. 0 objetivo desse artigo é sintetizar uma dosagem que utilize EPS para reduzir a massa especifica da argamassa de enchimento. Além do EPS, foi utilizada nas dosagens a Cinza de Madeira de Eucalipto (CME) a qual é descartada pelas indústrias de celulose. O segundo objetivo dessa pesquisa é investigar o caráter pozolanico do CME e a reutiliza-la na argamassa leve. A metodologia baseou-se na elaboração de três traços: o primeiro apenas com EPS, o segundo com EPS e substituição de $5 \%$ do cimento por CME, e o terceiro com substituição de $20 \%$ da areia média pela CME. Após a elaboração dos traços foram moldados corpos de prova cilíndricos de $5 \mathrm{~cm}$ de diâmetro e $10 \mathrm{~cm}$ de altura e executou-se a ruptura por compressão axial dos mesmos. Os resultados foram satisfatórios e os traços com EPS e CME tiveram resistências próximas (em torno de $4 \mathrm{MPa}$ ) e baixas massas especificas (em torno de 1300 $\mathrm{kg} / \mathrm{m}^{3}$ ), embora tenha ocorrido a diminuição da resistência com a utilização da CME, porém, pode-se dizer que a argamassa pode ser utilizada para enchimento de contrapiso.

PALAVRAS-CHAVE: Argamassa. Poliestireno expandido (EPS). Cinza de Madeira de Eucalipto (CME)

\section{SUMMARY}

The use of cement mortar is widely diffused in the works. The mortar is used for the laying of blocks, plastering and plastering of walls and for filling of subfloor and recesses of toilets. In the latter two cases, the lighter the mortar is the better for the load bearing structure, since the load due to its own weight will be better. To reduce the weight of filling mortars there are some materials that can be used as lightweight aggregates, such as: EPS, Vermiculite and expanded clay. The objective of this paper is to synthesize a dosage that uses EPS to reduce the specific mass of the filling mortar. In addition to the EPS, Eucalyptus Wood Ash (CME) was used in the dosages, which is discarded by the cellulose industries. The second objective of this research is to investigate the pozzolanic character of the CME and to reuse it in light mortar. The methodology was based on the elaboration of three traces: the first one only with EPS, the second with EPS and $5 \%$ replacement of the cement by CME, and the third with a replacement of $20 \%$ of the average sand by CME. After the traces were elaborated, cylindrical specimens of $5 \mathrm{~cm}$ in diameter and $10 \mathrm{~cm}$ high were molded and the rupture was executed by axial compression of the same. The results were satisfactory and the traces with EPS and CME had close strengths (around 4MPa) and low specific masses (around $1300 \mathrm{~kg} / \mathrm{m}^{3}$ ), although there was a decrease in resistance with the use of CME. it is said that the mortar can be used for subfloor filling.

KEY WORDS: Mortar. Expanded polystyrene (EPS). Eucalyptus Wood Ash (CME)

\section{RESUMEN}

La utilización de mortero cimenticia es ampliamente difundida en las obras. El mortero se utiliza para el asentamiento de bloques, embozo y revoque de paredes y para relleno de contrapiso y rebajes de baños. En estos dos últimos casos, cuanto más ligero sea el mortero mejor para la estructura portante, una vez que la carga debido al peso propio será mejor. Para reducir el peso de los morteros de relleno hay algunos materiales que se pueden utilizar como agregado ligero, tales como: EPS, Vermiculita y arcilla expandida. El objetivo de este artículo es sintetizar una dosificación que utilice EPS para reducir la masa específica del mortero de llenado. Además del EPS, se utilizó en las dosificaciones la Gris de Madera de Eucalipto (CME) la cual es descartada por las industrias de celulosa. El segundo objetivo de esta investigación es investigar el carácter pozolanico del CME y reutilizarla en el mortero ligero. La metodología se basó en la elaboración de tres rasgos: el primero sólo con EPS, el segundo con EPS y sustitución del $5 \%$ del cemento por CME, y el tercero con sustitución del $20 \%$ de la arena media por la CME. Después de la elaboración de los trazos fueron moldeados cuerpos de prueba cilíndricos de $5 \mathrm{~cm}$ de diámetro y 10 $\mathrm{cm}$ de altura y se ejecutó la ruptura por compresión axial de los mismos. Los resultados fueron satisfactorios y los rastros con EPS y CME tuvieron resistencias cercanas (alrededor de $4 \mathrm{MPa}$ ) y bajas masas específicas (alrededor de $1300 \mathrm{~kg} / \mathrm{m}^{3}$ ), aunque se produjo la disminución de la resistencia con la utilización de la CME, - se dice que el mortero puede ser utilizado para relleno de contrapiso.

PALABRAS CLAVE: Mortero. Poliestireno expandido (EPS). Gris de Madera de Eucalipto (CME) 


\section{INTRODUÇÃO}

O isopor, nome comercial dado ao Poliestireno Expandido (EPS), é um material muito utilizado não só nas embalagens de eletrodomésticos e demais produtos que são transportados de um lugar para outro, como também para preservar medicamentos contra altas temperaturas ou garantir equilíbrio térmico dos produtos armazenados no interior de recipientes feitos desse material, entre outras inúmeras finalidades. Diante desse cenário, sua utilização acontece em grande escala e com isso surgem vários problemas referentes ao descarte deste material, visto que o EPS possui grande potencial para causar danos ao meio ambiente (SANTOS, 2015).

Várias pesquisas mostram que é possível a utilização do EPS na construção civil como elementos estruturais, por exemplo, painéis de revestimento, paredes de cortina e sistemas de revestimento composto, ou até mesmo como camadas de proteção por possuir boa absorção de energia e na produção de concreto leve. Segundo Sayadi, Tapia, Neitzert e Clifton (2016), o concreto leve surge como uma alternativa ainda mais interessante em regiões que são suscetíveis a terremotos, já que a magnitude de um sismo é afetada pelo peso de uma estrutura.

Experimentos realizados em laboratório apontam que a adição de EPS no concreto resulta em maior relação resistência/peso, melhor resistência ao fogo, menor densidade e menor condutividade térmica, além de maior durabilidade, melhor capacidade de tração e isolamento acústico. Por outro lado, o tamanho e forma das partículas, o teor de umidade, a taxa de absorção de água e a superfície da textura colocam em risco às propriedades do concreto leve. Não é recomendado a utilização de grandes volumes desse material (SAYADI, TAPIA, NEITZERT e CLIFTON, 2016).

Segundo Mehta E Monteiro, 2008, alguns resíduos como cinzas volantes, sílica ativa e cinza de casca de arroz são utilizados em concretos leves por possuírem características que melhoram a interação com as partículas de EPS, contribuindo com o aumento da resistência.

De acordo com a ABNT: NBR 13281 (2005), a argamassa consiste em uma mistura homogênea que contém água, aglomerante inorgânico, agregado miúdo e, quando necessário, aditivos. A argamassa pode ser utilizada em assentamento, revestimento de paredes e tetos, de uso geral, para reboco ou até mesmo decorativa em camada fina ou monocamada.

Conforme consta na ABNT: NBR 6118 (2014), a argamassa de regularização e de nivelamento utilizada no contrapiso, por exemplo, visa corrigir as irregularidades e inclinação do piso, sendo utilizados traços que variam entre 1:5 e 1:7 (cimento e areia média) com quantidades de água o suficiente para se atingir a consistência desejada, com resistência média de $2 \mathrm{MPa}$.

\section{OBJETIVO}

O objetivo desta pesquisa é utilizar materiais alternativos, tais como: EPS e Cinza Moída de Eucalipto (CME), para confeccionar argamassa leve de enchimento de contrapiso. 


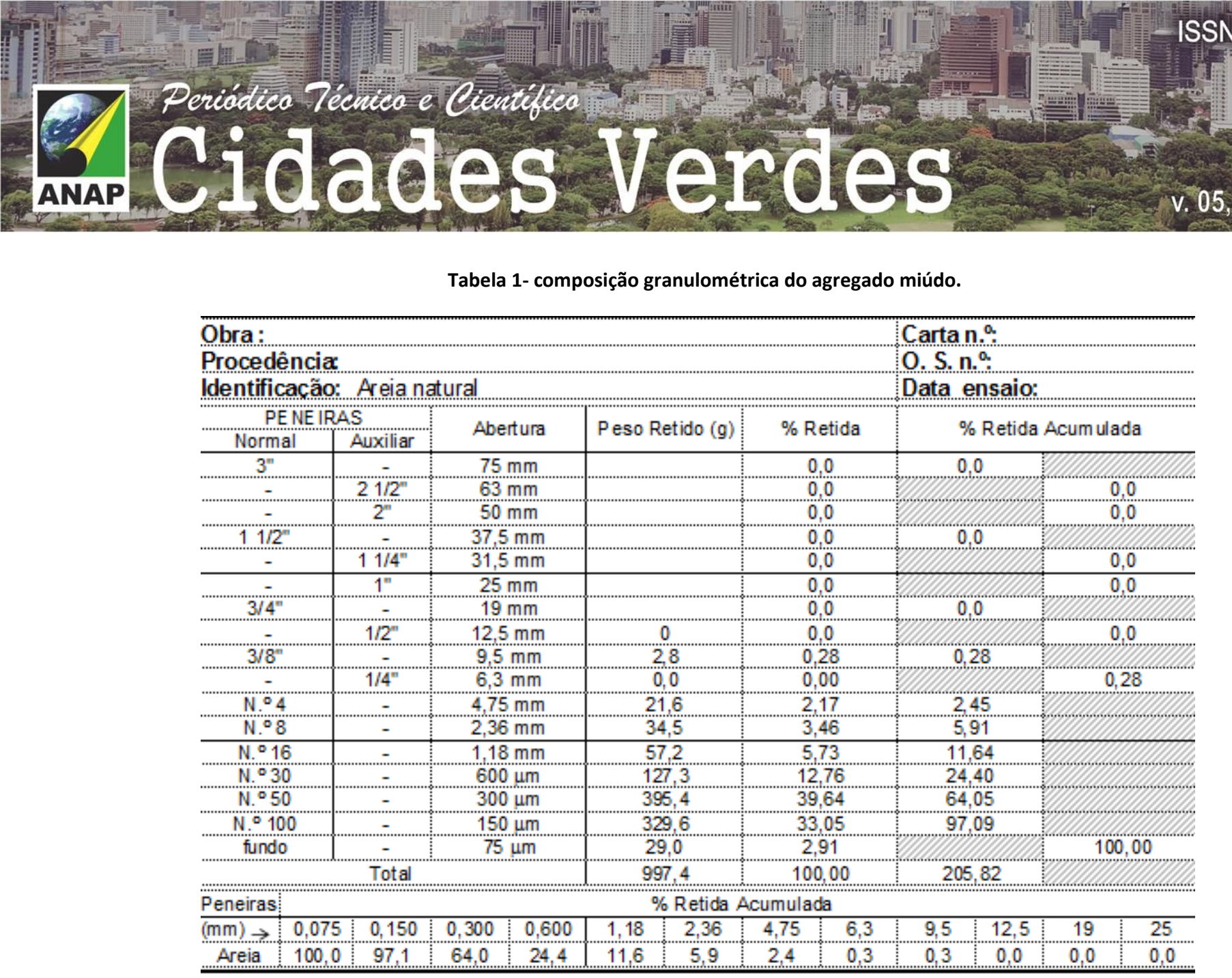

FONTE: Autor, 2017

Figura 1- Dispersão Granulométrica

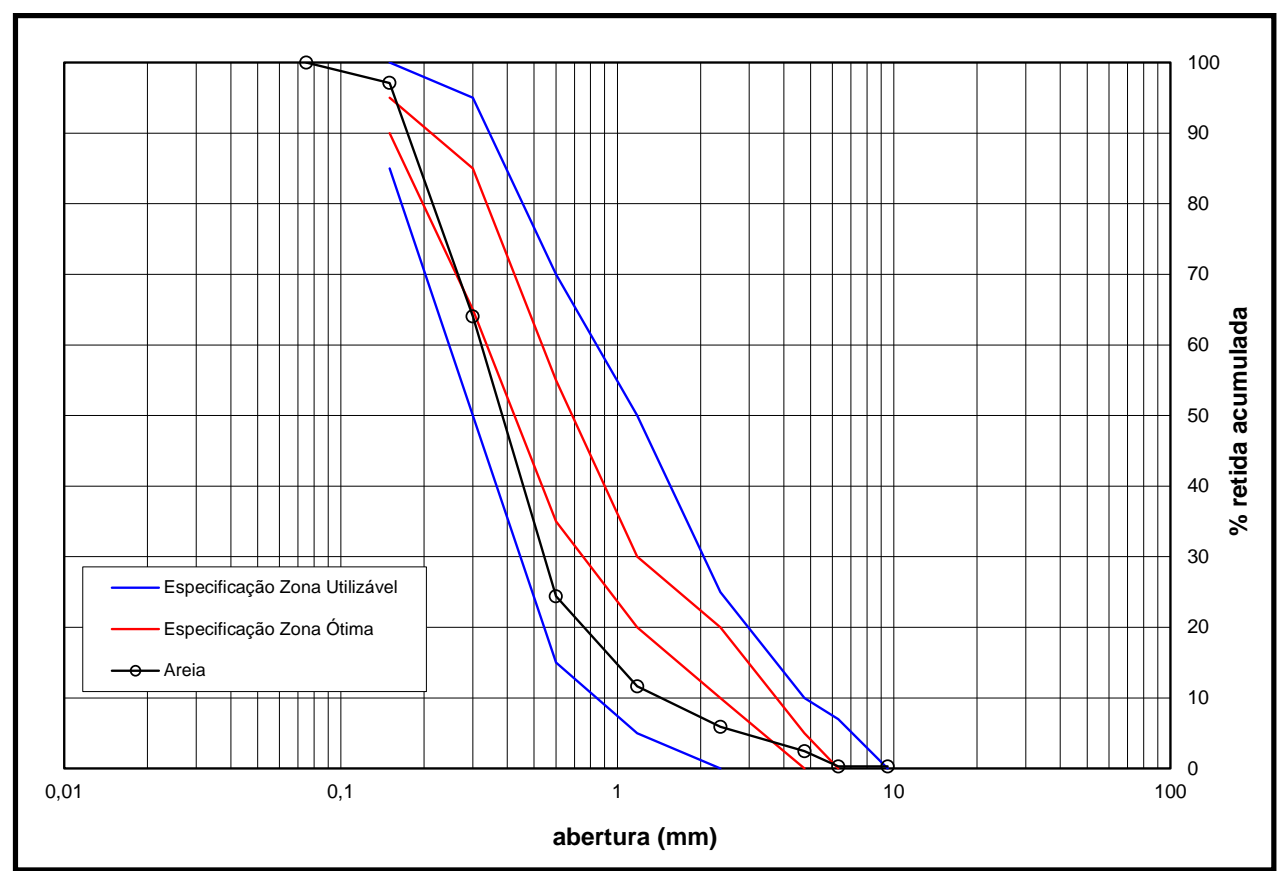

FONTE: Autor, 2017 


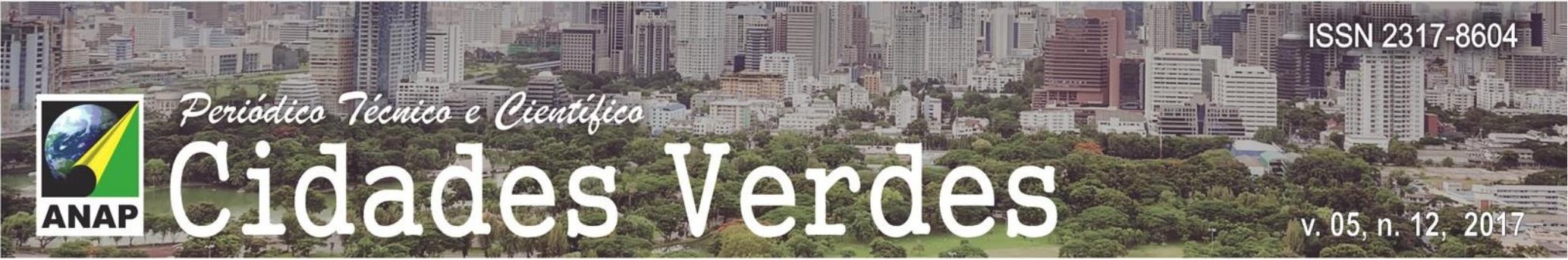

Tabela 2- Características físicas do agregado miúdo

\begin{tabular}{|c|c|c|c|c|c|c|}
\hline $\begin{array}{c}\phi \\
\text { máx. } \\
(\mathrm{mm})\end{array}$ & $\begin{array}{c}\text { módulo } \\
\text { de } \\
\text { finura }\end{array}$ & $\begin{array}{c}\text { S.s.s. } \\
\left(\mathrm{g} / \mathrm{cm}^{3}\right)\end{array}$ & $\begin{array}{c}\text { seca } \\
\left(\mathrm{g} / \mathrm{cm}^{3}\right)\end{array}$ & $\begin{array}{c}\text { aparente } \\
\left(\mathrm{g} / \mathrm{cm}^{3}\right)\end{array}$ & $\begin{array}{c}\text { solta } \\
\left(\mathrm{g} / \mathrm{cm}^{3}\right)\end{array}$ & absorção \\
\hline 2,36 & 2,06 & 2,630 & 2,600 & 2,660 & 1,700 & 1,21 \\
\hline
\end{tabular}

FONTE: Autor, 2017

\section{Poliestireno Expandido (EPS):}

O EPS foi coletado da empresa MEGA ISSO de Araçatuba, a qual, coleta resíduo de EPS utilizados em embalagens comerciais de lojas e descartadas em depósitos de lixo, processa-as e confecciona por meio de moagem, as pérolas de isopor conforme mostrado na figura 2.

Essas perolas são vendidas comercialmente para enchimento de estofados e também para utilização em concreto ou argamassa para enchimento de contrapiso, segundo a empresa.

\section{Cinza moída de Eucalipto (CME):}

Cinza moída de Eucalipto: as cinzas utilizadas são provenientes da cidade de Três Lagoas-MS, e foram extraídas de um fabrica de papel e celulose, ela é o resíduo final da madeira de eucalipto que já foi reaproveitada como lenha nas caldeiras de energia, 0 resíduo é mostrado na figura 3.

Figura 2- Cinza Moida de Eucalipto

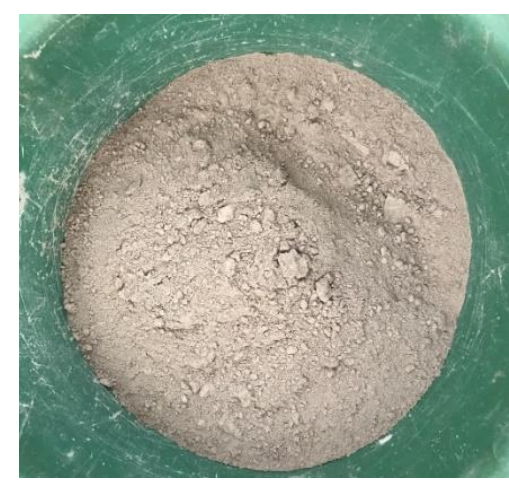

FONTE: Autor, 2017
Figura 3- Perolas de isopor

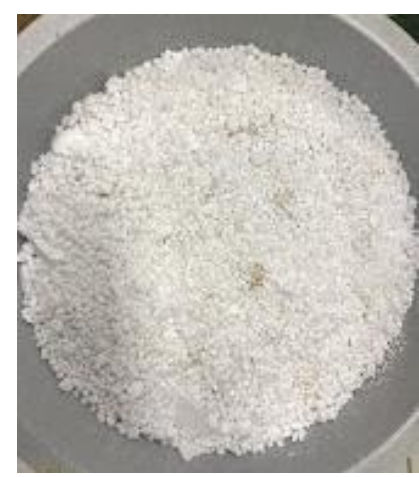

FONTE: Autor, 2017

Equipamentos e Instrumentos: 1 Balança de precisão 0,1 g; 1 Régua metálica ; 1 Molde rígido CP $\$ 5 \mathrm{~cm} \times 10 \mathrm{~cm} ; 1$ Soquete; 1 Mesa de consistência; 1 Trena; 1 Recipiente plástico; 1 betoneira, 1 Cronômetro; 1 Câmera fotográfica.

\section{Traços confeccionados:}

Nas tabelas de 3 a 5 são mostrados os traços confeccionados com os materiais descritos anteriormente. 


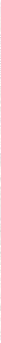

Tabela 3- Traço apenas com EPS (TC-EPS)

\begin{tabular}{l|r|c}
\hline \multicolumn{3}{c}{ Traços para $\mathbf{1} \mathbf{~ m}^{\mathbf{3}}$} \\
\hline \multicolumn{1}{c}{ Traços } & \multicolumn{1}{c}{$\mathbf{3}$} & $\mathbf{p}$ (Kg/l) \\
\hline 1:M & $1: 6: 2$. & - \\
\hline A/C & 0,5 & - \\
\hline EPC (kg) & 6,7 & 0,012 \\
\hline Areia grossa (kg) & 486 & 2,62 \\
\hline Cimento (kg) & 292 & 3,14 \\
\hline agua (kg) & 146 & 1 \\
\hline
\end{tabular}

FONTE: Autor, 2017
Tabela 4- Traço com substituição de $5 \%$ de Cimento por CME (TC-CME5)

\begin{tabular}{|c|c|c|}
\hline \multicolumn{3}{|c|}{ Traços para $1 \mathrm{~m}^{3}$} \\
\hline Traços & 3 & $p(\mathrm{Kg} / \mathrm{I})$ \\
\hline 1:M & $1: 6: 2$ & - \\
\hline $\mathrm{A} / \mathrm{C}$ & 0,5 & - \\
\hline EPC (kg) & 6,7 & 0,012 \\
\hline Areia grossa (kg) & 486 & 2,62 \\
\hline CME (kg) & 14,6 & \\
\hline Cimento (kg) & 277,4 & 3,14 \\
\hline agua (kg) & 138,7 & 1 \\
\hline
\end{tabular}

FONTE: Autor, 2017
Tabela 5- Traço com substituição de $20 \%$ da areia por CME (TC- CME 20)

\begin{tabular}{l|c|c}
\hline \multicolumn{3}{c}{ Traços para 1 $\mathbf{~}^{\mathbf{3}}$} \\
\hline \multicolumn{1}{c|}{ Traços } & $\mathbf{3}$ & $\mathbf{p ~ ( K g / l )}$ \\
\hline 1:M & $1: 6: 2$. & - \\
\hline A/C & 0,5 & - \\
\hline EPC (kg) & 6,7 & 0,012 \\
\hline Areia grossa (kg) & 388,8 & 2,62 \\
\hline CME (kg) & 97,2 & \\
\hline Cimento (kg) & 292 & 3,14 \\
\hline agua (kg) & 146 & 1 \\
\hline
\end{tabular}

FONTE: Autor, 2017

\section{RESULTADOS}

Os corpos de prova foram moldados e submetidos ao ensaio de compressão axial no Laboratório de Materiais de Construção Civil na UNIP de Araçatuba. As fotos da moldagem dos corpos de prova (CP) e de sua ruptura encontra-se nas figuras de 4 a 6 , na figura 7 podemos observar que o isopor ficou homogeneamente inserido na massa, não havendo segregação da mesma.

Figura 4- Materiais dosados para a confecção dos CPs.

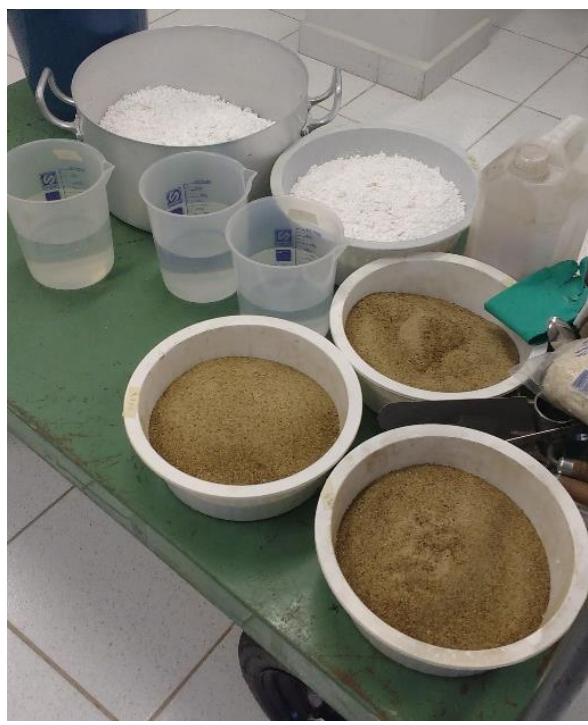

FONTE: Autor, 2017
Figura 5- Argamassa após a mistura na betoneira

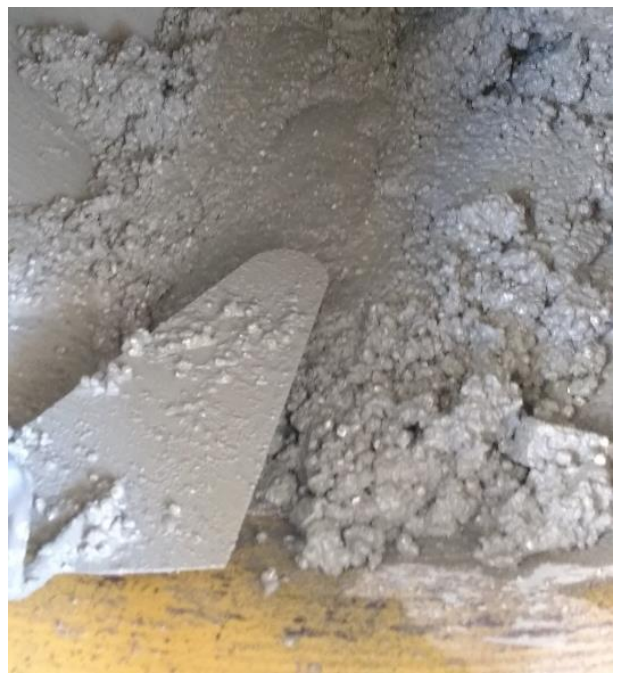

FONTE: Autor, 2017 
$\mathrm{Na}$ tabela 8 são mostradas as resistências atingidas por cada corpo de prova cilíndricos de $(5 \mathrm{x}$ $10 \mathrm{~cm}$ ) no ensaio de compressão axial, realizados ao 7 dias de idade, padronizada pela ABNT NBR 5739 (2007).

Tabela 8- Resistências atingidas por CP

\begin{tabular}{c|c|c|c|c}
\hline \multicolumn{5}{c}{ Resistencias Maximas } \\
\hline TRAÇO & Carga (kgf) & Area CP $\left(\mathbf{c m}^{2}\right)$ & Tensão $\left(\mathbf{k g f} / \mathbf{c m}^{2}\right)$ & Tensão (MPa) \\
\hline \multirow{3}{*}{ TC- EPS } & 1290 & 19,635 & 65,699 & 6,570 \\
\cline { 2 - 5 } & 1210 & 19,635 & 61,625 & 6,162 \\
\cline { 2 - 5 } & 1040 & 19,635 & 52,967 & 5,297 \\
\hline \multirow{3}{*}{ TC- CME 5 } & 740 & 19,635 & 37,688 & 3,769 \\
\cline { 2 - 5 } & 670 & 19,635 & 34,123 & 3,412 \\
\cline { 2 - 5 } & 530 & 19,635 & 26,993 & 2,699 \\
\hline \multirow{3}{*}{ TC - CME 20 } & 800 & 19,635 & 40,744 & 4,074 \\
\cline { 2 - 5 } & 1060 & 19,635 & 53,985 & 5,399 \\
\cline { 2 - 5 } & 1240 & 19,635 & 63,153 & 6,315 \\
\hline
\end{tabular}

FONTE: Autor, 2017

Na tabela 9 é mostrada a resistência média e o desvio padrão da amostragem. Para isso foi eliminado o a resistência do corpo de prova que mais destoou do espaço amostral. Na figura 8 é mostrado o gráfico com as resistências médias de cada traço.

Tabela 9- Resistencia Média e Desvio Padrão

\begin{tabular}{|c|c|c|c|c|}
\hline \multicolumn{5}{|c|}{ Resistencia média e desvio padrão } \\
\hline TRAÇO & Tensão (MPa) & Tensão média (MPa) & Desvio padrao & Redução da resistencia \\
\hline \multirow[b]{2}{*}{ TC - EPS } & 6,570 & \multirow[b]{2}{*}{6,37} & \multirow[b]{2}{*}{0,29} & \multirow[b]{2}{*}{$100 \%$} \\
\hline & 6,162 & & & \\
\hline \multirow[b]{2}{*}{ TC - CME 5} & 3,769 & \multirow[b]{2}{*}{3,59} & \multirow[b]{2}{*}{0,25} & \multirow[b]{2}{*}{$44 \%$} \\
\hline & 3,412 & & & \\
\hline \multirow[b]{2}{*}{ TC - CME 20} & 4,074 & \multirow[b]{2}{*}{4,74} & \multirow[b]{2}{*}{0,94} & \multirow[b]{2}{*}{$26 \%$} \\
\hline & 5,399 & & & \\
\hline
\end{tabular}

FONTE: Autor, 2017 


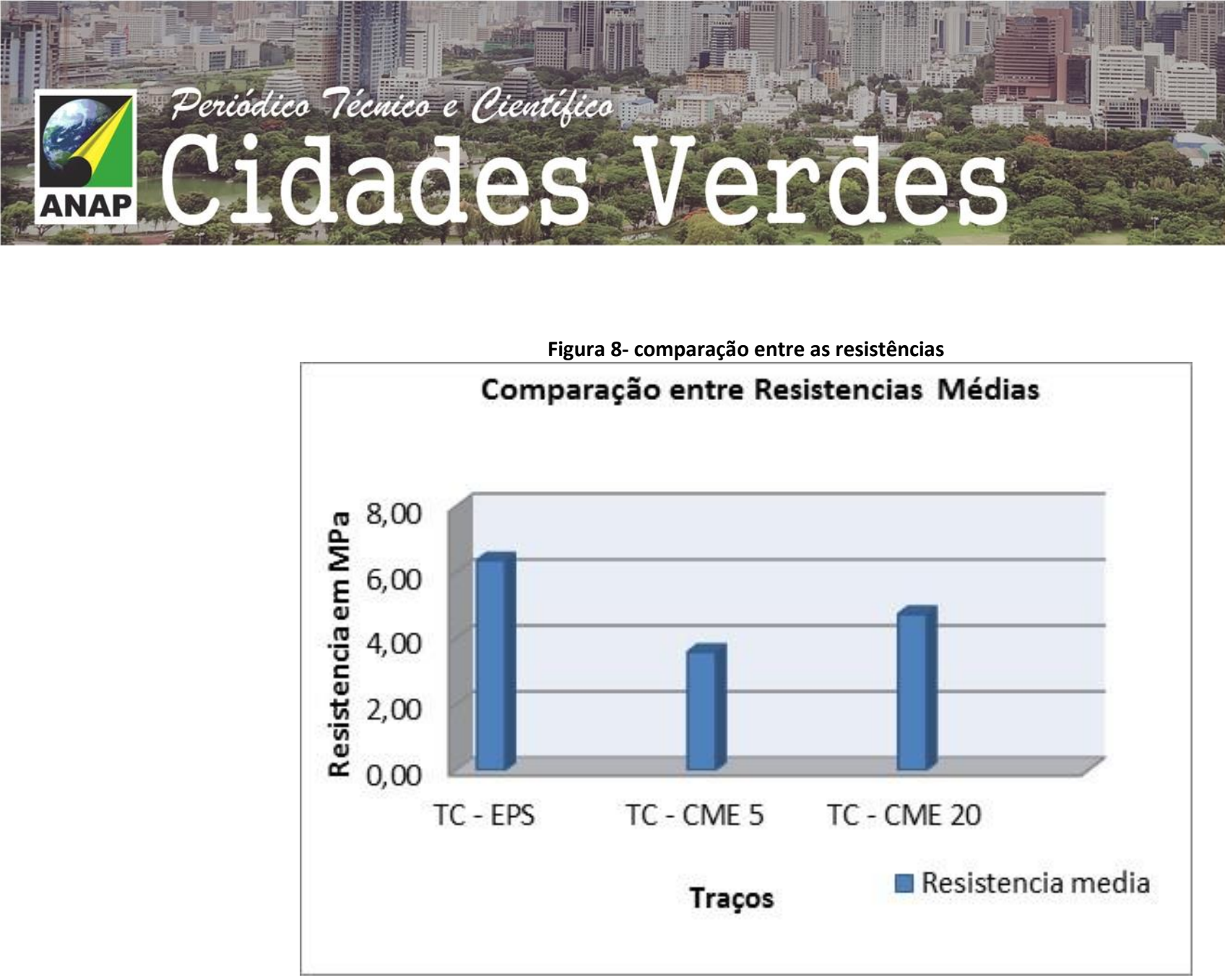

FONTE: Autor, 2017

A resistência média, ao substituir a CME tanto pela areia quanto pelo cimento, diminuiu. A maior diminuição ocorre ao substituir parte do cimento pela CME. Dessa maneira nota-se que a cinza não atuou como uma pozolana, ou seja, não conferiu maior resistência ao concreto endurecido.

\section{CONCLUSÃO}

Os resultados mostram que a argamassa confeccionada pode ser utilizada em contrapiso. Mesmo que a resistência a compressão diminuiu com os testes feitos. No entanto os testes de resistência foram realizados em idades pequenas, 7 dias, e dessa maneira não se pode dizer que o material tem ou não compostos pozolanicos que reagem em altas idades (após 30 dias) com o hidróxido de cálcio livre do concreto. Assim deve-se repetir os testes e realizar as rupturas em idades maiores.

Além disso, a resistência mais baixa encontrada 2,6 MPa, condiciona a argamassa a ser utilizada como contrapiso, o qual, não possui características resistentes e sim apenas de enchimento.

Pode-se concluir também que o EPS conferiu um caráter de argamassa leve aos traços com massas especificas em torno de $1300 \mathrm{~kg} / \mathrm{m}^{3}$. Este fato deixa sobrecarrega menos as estruturas e faz com que os projetos gerem consumos menores de aço. 
Por fim, a destinação final tanto do EPS quanto da CME, os quais iriam para aterros sanitários, pode ser alterada e os mesmos poderão ser reutilizados na argamassa de enchimento. Por exemplo: uma laje de $400 \mathrm{~m}^{2}$ de $7 \mathrm{~cm}$ de espessura irá consumir em torno de $28 \mathrm{~m}^{3}$ de argamassa que para ser feita necessitara de aproximadamente $2700 \mathrm{~kg}$ de CME e 15.000 litros de EPS, considerando o traço TC CME 20.

\section{REFERÊNCIAS}

ABNT NBR 13281. Argamassa para assentamento e revestimento de paredes e tetos Requisitos. Associação Brasileira de Normas Técnicas. 2005.

NBR 6118. Projeto de estruturas de concreto - Procedimento, Associação Brasileira de Normas Técnicas.2014.

NBR NM 248.Agregados - Determinação da composição granulométrica. Associação Brasileira de Normas Técnicas, 2003.

NBR NM 52.Agregado miúdo - Determinação da massa específica e massa específica aparente. Associação Brasileira de Normas Técnicas, 2003

NBR NM 30 Agregado miúdo - Determinação da absorção de água. Associação Brasileira de Normas Técnicas 2001.

NBR5739 .Concreto - Ensaios de compressão de corpos-de-prova cilíndricos. Associação Brasileira de Normas Técnicas 2007.

ECIVILNET. Argamassa de regularização. Disponível em: < http://www.ecivilnet.com/dicionario/o-que-e-argamassa-de-regularizacao.html>. Acesso em: 09/10/2017 às 20 h45.

ISAIA, G. C.: Concreto Ensino, Pesquisa e Realizações. IBRACON, Vol. 2.2005.

MEHTA P. K., MONTEIRO P. J. M.. Concreto: Estrutura, Propriedades e Materiais. Ed. PINI, 1a edição, São Paulo, 1994.

RESENDE, D.S.: Estudo do efeito da incorporação de cinzas de cavaco de eucalipto como material cimentício suplementar. Tese de Doutorado apresentada ao Programa de Pós-Graduação em Engenharia de Materiais da REDEMAT. Ouro Preto, Dezembro de 2013. Disponível em: http://www.repositorio.ufop.br/handle/123456789/4411 Acessado em 07 /09/2017.

SANTOS, M. A importância do isopor na construção civil. Disponível em: < https://blogdaengenharia.com/importancia-isopor-na-construcao-civil/>. Acesso em 09/10/2017 às $19 h 21$. 


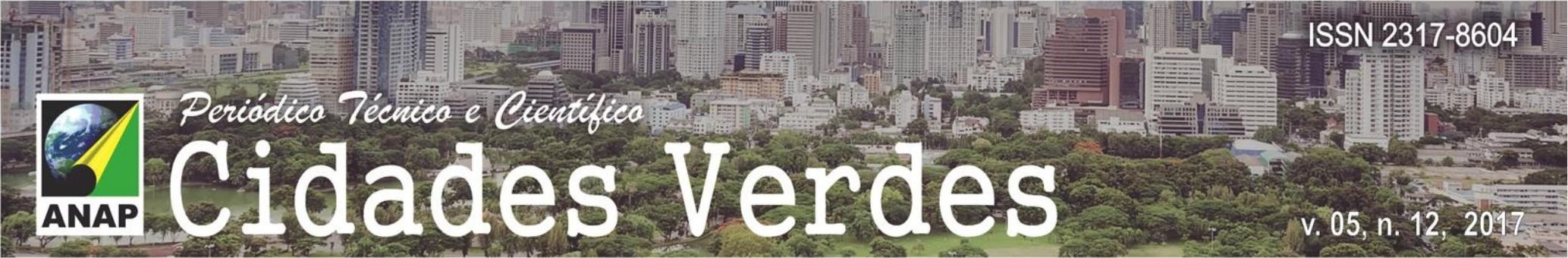

SAYADI A.A., TAPIA J.V., NEITZERT T.R. e CLIFTON G.C. Effects of expanded polystyrene (EPS) particles on fire resistance, thermal conductivity and compressive strength of foamed concrete. Construction and Building materials, Elsevier, 2016. Disponível em: http://www.sciencedirect.com/science/article/pii/S0950061816302756. Acesso em 05/10/2017. 